\title{
Language and society in text: Ahmed Yerima's Pari
}

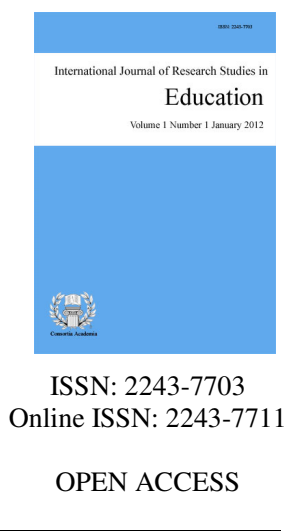

Adebola, Adebileje $\bowtie$

Redeemer's University, Nigeria (adebilejea@run.edu.ng)

Daniel, Florence

Redeemer's University, Nigeria (foluseyidaniel@gmail.com)

\section{Abstract}

This paper carries out a descriptive analysis of the systematic functions of language in the society as captured in a text. It foregrounds the fact that language effectively mirrors events and cultures of peoples far beyond their location to a global audience without necessarily living among them. The paper illustrates the interwoven nature of language and the society through text by analysing a play, Pari written by Ahmed Yerima. Pari depicts the woes and cries of some typical Nigerian families whose daughters were abducted by Islamic extremists, 'Boko Haram' in Chibok, a village in Northern Nigeria. Extracts from the text are analysed based on (Hymes, 1974) ethnography of communication theory which among other things is concerned with 'the description and understanding of communicative behaviour in specific cultural settings' (Saville Troike, 2003, p. 2). Using the SPEAKING acronym, ten extracts purposively selected from the speech events of the major participants (actors and actresses) in the drama text are analysed. Such language functions as informing, questioning, commanding, persuading and promising are revealed in such states of mind as serious, sorry, agitation, excitement and relaxed. These acronyms have strong implications for teaching and learning as they aid an instructor in achieving far-reaching results in a classroom setting in that they leave the students saturated with a thorough knowledge of the topic of discourse and in this case, a literary text.

Keywords: language; society; culture; ethnography; text 


\section{Language and society in text: Ahmed Yerima's Pari}

\section{Introduction}

Language as a medium of communication mirrors the society and its culture. Societal values can be reflected in its language as it mediates between the society and its culture. Language has a social function of helping to establish and maintain relationships. In other words, it facilitates social communication and nurtures mutual cooperation. Leech (1974, p. 49) is of the view that language has five functions: informational, expressive, directive, phatic and aesthetic. On the other hand, Douglas (2000, p. 252) classifies the functions of language into seven. These include: the instrumental function, which serves to manipulate the environment to cause certain events to happen; the regulatory function used to express approval or disapproval; the representational function used to make statements, facts and knowledge, and to represent reality as one sees it; the interactional function which serves to ensure social maintenance; the personal function which allows a speaker to express feelings, emotions and personality; and the heuristic function which is used to acquire knowledge and learn about the environment. However, the kind of language used by individuals is determined by their social background as it reveals information about its users. Thus, to understand a people, their culture and perspectives towards certain events in the society, literatures (texts) from such a locale serve as useful artefacts for such ends. This supports the assertion made by (Kerby, Goodpaster, \& Levine, 2002, p. 94) that 'Language is the landscape of our mind; it is the mountains and forests as well as the cities and roads'.

As explained by (Blommart \& Maly, 2014, p. 2), 'language is the most immediate and direct identifier of people and the most immediately sensitive indicator of social change'. It helps to discover the characteristics and direction of societal processes of change even long before such changes are recorded in official documents. From another perspective, language is regarded as 'the hallmark of people and their culture' as it 'encompasses their worldview, custom, way of life and history in general' (Balogun, 2013, p. 70). There is therefore a strong link between language and the society as society is responsible for shaping an individual. As a social being, man imbibes the social norms, tradition and culture of the society in which he finds himself and he depends solely on language to achieve these. Thus, language is 'a necessary means of communion; it is the one indispensable instrument for creating the ties of the moment without which unified social action is impossible' (Diamond, 1959, p. 12).

The notion of a text suggests in part, the storing of people's culture through language, be it drama, printed books, proverbs, symbols or music. It also suggests an expressive function of language which is best demonstrated by text: poetry, drama, fiction and many others. For instance, when writing a text, the author is not only concerned with passing on information but also attempts to communicate personal feelings and sentiments. Expressive language is not only used by authors, but by all people when they want to give expressions to their profound and intimate feelings. This study therefore, seeks to explore the expressive function of language in text as it projects the security realities in Northern Nigeria. Also, the linguistic tools used in exploring this language function is meant to expose learners and teachers alike to linguistic resources that can possibly be harnessed in the teaching and learning of literature, a mirror of the society. Thus, the study demonstrates the usefulness of ethnographic tools in the teaching/learning as well as the understanding of literature.

Previous ethnographic studies have examined literary texts and other discourse activities such as doctor and patient discussion (Unuabonah, 2008), drama text (Adebola \& Atunde, 2014), classroom discourse (Hepburn, 2016), bargain discourse (Umezinwa, 2017) among others. These are different from the present study. For instance, (Adebola \& Atunde, 2014) examines Osofisan's The Midnight Blackout using a combination of the SPEAKING acronyms and Grice's principle to explore the interrelatedness of society and language, which differs from the present one in the drama text studied and the goal of the present study. Other existing ethnographic studies have applied the linguistic tools to other discourse situations different from the present one 
which stands the present study out from them. Aside these facts, the selected text for this present study is a recent publication (2016) and it is still yet to be ethnographically analyzed as far as we know. The study therefore seeks two distinct goals; first to underscore the immense role language plays in projecting any society to the world and second to demonstrate the usefulness of the acronyms in teaching and learning literature.

\subsection{A brief background to the text}

Ahmed Yerima's Pari, a drama text centres on the issue of the Islamic extremists who kidnapped over 200 girls in 2014 in Chibok, Borno state, Nigeria. The play text presents the fate of parents, especially, the mothers who lost their children to the incident and the attendant physical, mental, psychological, and religious imbalance they suffer. Through a narrative and dialogic mode, the author skilfully uses language in the text to project the affected people's reaction to the widespread claim of some government officials on the reality of the abducted secondary school girls.

The play begins with Ama (originally christened Agnes) the mother of an only child, who is among the abducted girls, engrossed in an Islamic prayer. Upon the abduction of her only daughter, she converts to Islam hoping that the god of the abductors will show her pity and cause the release of her daughter. Her husband, Tada (a deacon) finds her in the Islamic praying position and regalia and engages her in an argument which yields no result. Their daughter's abduction and Ama's inability to give birth again makes her in-laws send a young girl (Jiga) to their home under the pretence that they both need someone to run errands for them. This leads into an illicit relationship between the girl and Tada, who impregnates her. This complicates Ama's problem and makes her vacillate from one religion to the other. She consults an herbalist who predicts that her daughter will return but tells her to be ready to release her, a prediction which is not so clear to her. Still in the mood of depression and frustration, prayer is arranged for the return of Pari, their abducted girl but could not hold, because those expected for the prayer get distracted by another attack which at this time claims thousands of lives including close relatives of Ama and Tada. These events leave their faith in God terribly shaken, thus, leading Tada, a deacon, into drunkenness, and Ama into fetish acts.

Pari (the abducted daughter) is eventually brought home by a local government chairman but has completely changed from the innocent girl her parents once knew. She returns with a baby she gave birth to while in Sambisa, the abductor's camp. Her parents, who are left with no other option, receive her with mixed feelings and make efforts to stabilize her, but things will never remain the same with her. She recounts her experiences in the abductors' camp and the tale behind the child she brought, who is a twin, and how she killed the other twin, who was a girl for the fear of her getting raped someday as she (the young mother) was. Not long after that, a young man named Ibrahim visits Ama's home seeking Pari's hand in marriage. He identifies himself as her husband in Sambisa. The parents, who are both frightened and angry could not but receive him for the sake of their newly returned girl. Ama, gives him food and herbal medicines with an intention to strangle him when he is deeply asleep. The plan is interrupted by Tada who talks her out of it.

The couple thereafter engages Ibrahim who recounts his ordeal in the camp of the Islamic extremists, what led him there initially and his resolve, which is to lead a peaceful life afterwards in the company of Pari, a proposition which is rejected by Pari's parents. She earnestly pleads to be allowed to go with him as that is the only option she believes she has. After much ado, she is allowed to go with Ibrahim, who Ama converts to Christianity, naming him Abraham and teaching him the Lord's Prayer, in a make belief manner though.

In the text Pari, Yerima uses a blend of English and Hausa languages to make the text communicate the depth of the grief in the hearts of the embittered parents. Also, he uses the domesticated version of the English language to project the 'Nigerianness' of the situation he writes about. There is an incessant use of the Hausa language directly without interpretation possibly to create a special effect which suggests the kind of imposition and tribalism reigning in the country. He effectively projects the menace of religious extremism in the Nigerian society and the views of the sufferers with the use of simple words. This is not far from the fact that the reported 
audience are not so educated, hence, the need for the language variety that will best depict the cries of these poor and distressed people who have been deprived of almost everything meaningful that life can offer. To the Nigerian society at large, the language expresses the frustrations of the destitute, in such words and tones that send the message home and faster. The tone is both harsh and mild. Harsh in the scenes that involve Ama, the grieving mother who wants nothing but the return of her only child, and mild in such instances where Tada applies religious caution on the rather harsh and impatient wife, who will spare no word in expressing her worries and anger at her fate.

Most of the characters in the text are rural people who use the Hausa language in actual situations but are made to use the English language to reflect the rural community and the typical thought patterns of the rural Hausa community. This, Yerima does by his use of images and similes typical of the Nigerian and Hausa community especially. These expressions though grammatically meaningful are stylistically foregrounded to create an imagistic effect. A number of scholarly attempts have been made on Yerima's plays; Pari is one of his most recent plays, published precisely in 2016. So far, no linguistic analysis of the text has been done, especially as it concerns Ethnography of Communication.

\section{Theoretical framework}

The analysis of extracts from the text is hinged on Hymes (1974) ethnography of communication which among other things is concerned with 'the description and understanding of communicative behaviour in specific cultural settings' (Saville-Troike, 2003, p. 2). According to Adebileje and Atunde (2014, p. 136), 'it deals with the naturalists' creativity in human communication and not necessarily on the correctness or lack of it in naturally occurring conversations'. Hymes (1974) SPEAKING acronyms propounded as tools used in identifying the many sides of a discourse as well as its contextual features are engaged in this paper to identify and describe the discourse features in the text, Pari. The acronyms are described as follows:

$>\quad S$ - Setting or Scene is the particular place and time a speech event takes place.

$>\quad P$-Participants according to (Saville-Troike, 2003, p. 114) include not only speakers, but also hearers and over hearers, a description which includes not only observable traits but also background information such as the participants' age, sex, ethnicity, social status, among others.

$>\quad E$ - End has to do with the aims and goals of a speech event different from others.

$>\quad$ Act refers to the form and content of the message which includes the instance of topic and topic change. For example, a change in the topic of discourse in a speech event may mean a change in the style of the speaking.

$>\quad K$ - Key has to do with the tone, manner or spirit in which an act is done (Hymes 1972, as cited in Saville-Troike, 2003, p. 113). As further opined by Saville-Troike, key is culture-specific and must be determined based on indigenous perceptions. It may be signalled by choice of language or variety, by non-verbal signals, by paralinguistic features or a combination of elements.

> I- Instrument means the channel or mode of communication which may be verbal or non-verbal.

$>\quad N$ - Norms refer to the specific rules which are relevant to the communicative event. These according to (Saville-Troike, 2003, p.123) are prescriptive statements of behaviour of how people are expected to act, which are in turn tied to the shared values of the speech community.

$\quad G$-Genre means the type of the event which could be a story, a joke, a conversation and many others.

\section{Methodology}

Using the SPEAKING acronyms explained in section two, the study analysed ten extracts purposively 
selected from the speech events of the major participants (actors and actresses) in the drama text. Such were chosen because they are the ones around whom the story revolves-the major characters. The selected character names are pseudonyms not the real names of the victims discussed in the book. Also, the particular extracts chosen among many others said by the major actors and actresses are the focal speeches of the various scenes in the text. Each represents a major part of the story which builds from the rising action to the climax. After the selection, each letter in the acronym was applied to each extract to derive answers to questions on the Setting, Participant, End, Act, Key, Instrument, Norm, and Genre. Answers on Setting, End, Instrument, Norm and Genre were qualitatively discussed because they provide general information on the text while those of Participants, Act and Keys were both quantitatively and qualitatively analysed to provide more specific depth in the understanding of the text.

\subsection{Ethnography of communication in the selected extracts}

\section{Extract 1}

Ama: But all I know is that the dreaded village masquerade of Mbalala dances only to the sound of the drums his followers play. From now on, I believe it is the right thing to do. If you take what is mine forcefully, and claim that it is right in the sight of a god... your God... and you get away with it, then I want to know why? And I want to know what language your God understands... when he sleeps... what he eats. I just want to know what humanity they stand for. I just want to know, Jacob. Am I wrong, Husband? Am I in the wrong? (Pari, p. 9)

In this extract, Tada meets Ama where she is observing the Islamic prayer and engages her in a conversation questioning her sudden change from Christianity to Islam. The Setting of extract one is a scantily furnished sitting room. The Participants are Ama and Tada (parents of one of the abducted girls). The End is for Tada to let Ama be in her newly chosen religion as she believes the god of the religion will pity her and release her child. The Act is informative and questioning, involving lots of question marks and said in a serious tone, as Ama is convinced that conversion to Islam is the solution to her problem. The Instrumentality reveals that it is a verbal communication from Ama to Tada, while the Norm is for Tada to be convinced himself and let her be. The genre is dramatic.

\section{Extract 2}

Tada: Agnes, I feel... truly feel the absence of Pari, too. I am her father, remember? She is my blood, too. It was the devil. I never knew I was walking into a trap when Jiga was brought to stay and help us with house chores. I never knew that was a trap by my family. I feel so stupid now. All I was told was that she was to be a shoulder for us to lean on. I am deeply sorry. A bush shoulder has become a fish bone I cannot swallow. (Pari, p. 12)

In extract two, Tada responds to Ama's accusation on her husband's infidelity which has resulted in Jiga's pregnancy. Jiga was sent to them after the abduction of their only child to run errands but was impregnated by Tada. The Setting is the sitting room and the Participants are Tada and Ama. The End is for Ama to be persuaded, as Tada tries to make his wife reason along with him. The Act is informing, said in a sorry tone. It is a verbal communication said by Tada to Ama and the Norm is for Ama to forgive him of his infidelity. The genre is a dialogue.

\section{Extract 3}

Luke: The dreaded boys attacked, burnt and killed thousands of our church members in Mubi and Uba. They burnt down the churches ... killed even the pastors. Sister Vero escaped. She was home, having just lost her pregnancy... but Reverend John gave up the ghost while gallantly fighting for Christ. (Pari, p. 19) 
In extract three, Luke and his wife visited the Tadas who expected them and other church members for a prayer meeting for the release of Pari. Upon their visit, they inform them of the latest news of another attack on their church which claimed thousands of lives. The Setting of the communicative event is a part of the Tadas' house, probably the sitting room as it reveals Ama sitting on a mat. The Participants are Ama, Tada, Luke (a Reverend) and Sister Hanna. The End is for the Tadas to know the latest occurrence. The Act is informing while the Key is that of agitation. The speech event is in a verbal mode. The Norm is for the Tadas to be informed on the recent happening in the church which consequently cancels the prayer meeting earlier planned. The discourse is a dialogue.

\section{Extract 4}

Ama: Salvation? Of whom? For whom? Whose salvation? Please tell me, Wise man. (Shaagu begins to murmur.) Am I to prepare for some special event of upliftment soon? Is it a burial or a homecoming? My nightmare affects my dark aerial fancies, which show me frightening images, all pointing towards the direction of death. Which one will it be, Wise man? In my haunting dreams, I have... (Pari, p. 26)

Here in extract four, Ama seeks the service of a seer with the help of her sister Cheche who brings him to Ama's house. The man tells her what he sees through his magic mirror but is not clear to Ama, so she asks questions. The Setting is Ama's house, and the Participants are Ama, Cheche, and Shaagu, (the Wise man). The End is that Ama wants to be clear on what Shaagu revealed through his magic mirror. The Act is questioning, as it involves the use of multiple question marks. The Key is agitation and the Instrumentality reveals an oral communication. The Norm is for Shaagu to clarify his earlier predictions on salvation. The genre is dramatic.

\section{Extract 5}

Shaagu: I am not the kind of prophet you desire. I walk only within the given light of the spirit. My eyes open only when the eye of the mirror opens. They give me sight, but only for a while. See how the spirit of the mirror gallops away on his white horse. Now blankness is restored. My job here is done. Woman, you shall smile soon and when you do, do not let the joy of your heart mingle too much in your thoughts of pain. (Pari, p. 27)

In extract five, Shaagu the seer responds to Ama's many probing questions after he had told her his findings. The Setting here is Ama's house and the Participants are Ama, Shaagu, and Cheche (Ama's sister). The End is that Shaagu cautions Ama on her quest for more information than is available and lets her know that she will smile soon. The Act is informing, said with a tone of finality (serious). For instrumentality, it is a spoken discourse and the Norm is for Ama to take what he had said as final and ask no further questions. The Genre is a dramatic.

\section{Extract 6}

Kalagu: I want to see the mother of this house. We received a paper from Chibok Local Government that your daughter Hyelapari Shettima was one of the girls kidnapped from the Government Girls Secondary school, Chibok on the night of the $14^{\text {th }}$ of April, 2014. Is this true? (Ama does not answer) Please, answer, madam. (Pari, p. 29)

In extract six, Kalagu, a local government chairman visits Ama's home in the company of some military men and Pari, Ama's abducted daughter. He asks for the mother of the house to make some enquiries. The Setting again is Ama's house, the sitting room and the Participants are Kalagu, Pari and a child and Ama who later joins them. The End is that Kalagu wants to confirm if actually Pari was one of the kidnapped girls. The Act is questioning and in a serious tone, orally communicated. The Norm is for Ama to cooperate with them and supply the information needed. The genre is dramatic. 


\section{Extract 7}

Pari: It was a dry night in school. Everything went on normally. We had dinner and we were preparing for prep... then all of a sudden, there was commotion. Gun-totting men, about two hundred, entered the school. There was no light in school, so the darkness helped their cause. We were frightened to the bones. Then they started to gather us together towards the gate. Some girls were lucky, they were able to escape at the time, but I was petrified... frozen with fear. (Pari p. 35)

Extract seven shows Pari narrating the event of her kidnap to her parents. The Setting is Ama and Tada's home and the Participants are Ama, Tada, and Pari. The End is for her parents to know what actually happened on the day she was kidnapped. The Act is informing said in a rather relaxed tone, orally communicated. The Norm of speaking is for the parents to know about the event of her kidnap and the Genre is a dialogue.

\section{Extract 8}

Ibrahim: What about him? Him too. We had predicaments strewn all over... and God stood silently by. We were ready to burn and blow up the sky where we believed he lived in smugness and allowed life to pass us by. Even after a while, the promise that we would go straight to aljana faded. With time, the Aljana we believed was what we created. It was nowhere but where we stood we were the gods in the aljana we created. With guns and bombs, even Allah was afraid of us. (Pari, p. 47)

Here we meet Ibrahim, one of the Jihadists who impregnated Pari in the Jihadists' camp. He had escaped from the war front and came in search of Pari. Though he was received hesitatingly, he is seen seated and eating in Pari's house and narrating his ordeals in the Jihadists' camp. The Setting is Pari's house with Pari's parents and him as the Participants. The End is to satisfy his in-law's curiosity while the Act is informing. The Key is excitement shown in such statements like with guns and bombs, even Allah was afraid of us! and the Instrumentality shows an oral discourse. The Norm is for Pari's parents to be informed on how dreadful the Jihadists are. The Genre is dramatic.

\section{Extract 9}

Tada: Agi stop! By the gods, what are you trying to do? What were you trying to do? This is the father of your grandson for Christ's sake. (Pari, p. 56)

Ama who is bent on avenging the ill treatment of her daughter on Ibrahim, attempts killing him with a knife after giving him an overdose of a herbal medicine. Here Tada stops her from committing such an act. The Setting is Ama's house with Ibrahim fast asleep on the floor. The Participants are Tada, Ama, Ibrahim, and Pari (also sleeping). The End is for Ama (also known as Agi) to desist from such an act. The Acts here are commanding, questioning and persuasive while the Key is agitation. The Instrumentality shows an oral communication and the Norm is for Ama to stop what she is about to do. The genre is also dramatic.

\section{Extract 10}

Ibrahim: I swear by Allah, I shall come back for my son... and maybe her... if she wants me (He kneels by Pari). Pari I am sorry... I have not been a good man to you, I am sorry I am who I am. Maybe if the circumstances were different... I may have been different too. But I swear, I shall watch and keep you and our child like all good men should. So I shall return for you... (Pari, p 65)

Earlier, plans had been made by Tada and Ama to get Ibrahim away from them for safety and for the sake of their daughter. In this extract, Ibrahim promises to return for his son and Pari if she so desires and to turn a new 
Adebola, A., \& Daniel, F.

leave. The Setting is Pari's parents' house and the Participants are Ama, Tada, Ibrahim and Pari (who is lying on a mat). The End is for Pari to be assured that he will return for her and their son, in a promising Act. It was said in a sorry tone and the Instrument is oral. The Norm is for Pari to expect his return as he turns a new leave. The Genre is dramatic.

\section{Results and discussion}

\subsection{Analysis and interpretation of data}

A quantitative and qualitative analysis and interpretation of the data analysed above is necessary to fully recover the workings of the SPEAKING acronyms earlier analysed in the extracts. They are presented in tables below. In terms of the Setting, majority of the scenes took place in the house of the major characters (Ama and Tada). This may not be far from the simple fact that they are the ones around whom the story revolves.

\section{Table 1}

Participants in the text

\begin{tabular}{lc}
\hline \multicolumn{1}{c}{ Participants } & Frequency \\
\hline Ama & 6 \\
Tada & 4 \\
Pari & 3 \\
Ibrahim & 3 \\
Luke & 2 \\
Hanna & 1 \\
Shaagu & 1 \\
Kalagu & 1 \\
Cheche & 1 \\
Zeer & 1 \\
\hline
\end{tabular}

The total number of characters or Participants who featured in the play is ten. The main characters are Ama, Tada, Pari and Ibrahim. As displayed in the table, Ama has the highest number of occurrence in the play. She is the main character who plays a defining role in the play in that she represents thousands of Nigerian women who had lost children to this menace and the social realities they had to face as victims and recipients of the hazards of religious extremism. She is also put at the fore to project Yerima's view on the plight of the female folk in such matters as insurgence in the society.

Tada's number of occurrence is also high, being the father of the abducted girl but not as high as Ama's. In the text, Tada is projected as a drunk and an adulterous man who is not so bothered about the missing girl. Thus, the playwright presented him thus to reveal the degree of concern men display in the heat of problems in the home front and seems to say that females are more sufferers than males in such burning issues as the one presented in the text.

Pari is also a major character in the play, an eponymous one at that. Her name is the title of the text and so she plays a major role in the text as a witness to doubtful minds who believe that the Chibok girls' school kidnap news was only a political propaganda. Ibrahim also featured in the text to give a clue on the Jihadists' perspective. Reverend Luke and Sister Hanna represent the church while Shaagu represent the traditional religion. Kalagu plays the role of government officials in the text, a minimal role at that, a pointer at the failure of the government and the sufferers' perspectives on the roles of the officials. Other characters in the text are Cheche, and Zeer, both served as minor characters in the play.

\subsection{Analysis of the acts in the analysed texts}

Table 2 contains Acts found in the analysed texts and the frequencies. The informing act has the highest 
frequency of 6 , followed by the questioning act. The commanding, persuading and promising acts have the frequency of one each. Yerima treats the important issues in the texts through the informing and questioning acts, in that he gives voices to the major characters to air their frustrations and the many issues in their hearts are projected through the questioning act. These five acts reveal the degree of seriousness attached to each context the acts represent.

Table 2

Acts in the analysed text

\begin{tabular}{lc}
\hline \multicolumn{1}{c}{ Acts } & Frequency \\
\hline Informing & 6 \\
Questioning & 4 \\
Commanding & 1 \\
Persuading & 1 \\
Promising & 1 \\
\hline
\end{tabular}

The informing act which ranks the highest exposes the minds of the major characters, victims of the extremists' activities to the readers, thus, aiding the understanding of the text. The informing act also serves as linkers in the story, thus creating a link between the previous scene and the next. For example, in pages 19 and 35, Reverend Luke and Pari give two different information which help to fill in possible lapses in the readers' interpretation and understanding of the text. Reverend Luke tells Ama and Tada of the latest attack on their church which results in the cancellation of the prayer meeting earlier scheduled. Pari also narrates the event of her kidnap, stay in the abductor's camp and series of events that happened to her while there. These flashbacks in a way authenticate fragments of news the readers must have heard about the whole ordeal. Also through this act many other hidden information about the operations of the Jihadists are revealed to give a full dose of information to the readers which may not be fully relayed for the shortness of time and space in the drama text.

The questioning act is the next. Yerima, through this act reveals the hidden questions, troubles and agitations in the minds of the major characters. Through this technique, the reader is made to see the degree of frustration in the affected mother's heart and in a way moves the readers to feel for the parents of the abducted children and people across the country.

The commanding and persuading acts were used in a single speech event. The character involved in this act is Tada, upon Ama's attempt at murdering Ibrahim. He immediately switches into persuasion with the aim of talking her out of the act. The promising act is also deployed in the text and it involves Ibrahim, at the point where he is to go away from the Tadas. It also has the least occurrence.

\subsection{Analysis of the number of keys studied}

Table 3

Keys studied in the text

\begin{tabular}{lc}
\hline \multicolumn{1}{c}{ Keys } & Frequency \\
\hline Serious & 3 \\
Sorry & 2 \\
Agitation & 3 \\
Excitement & 1 \\
Relaxed & 1 \\
Total & 10 \\
\hline
\end{tabular}

The Keys displayed in the table above reveal the state of mind of the discourse participants in the text. The serious and agitation key have the highest occurrence because the matter at stake and the issues being discussed require much seriousness which results in a number of speech events spoken with agitation. The sorry Key was reflected in the speech events of Tada and Ibrahim, the male figures who had to make up for their wrong deeds. In terms of occurrence, it is next as high as the first two Keys earlier mentioned. The excitement Key (which has 
the least occurrence) was displayed in Ibrahim's informing act where he slipped into excitement in the process of recounting his experiences in the Jihadists' camp. The relaxed Key also has the least occurrence in the text and is reflected in the discourse of Pari as she narrates her experiences and the event leading to her kidnap. These Keys to a large extent reflect the personality of the characters in the play, thus lending the reader an incline into the realities surrounding each of them.

\section{Conclusion}

The analysis of the play Pari reveals that in any society, there exists a synergy, between culture and the people. Language being an instrument of cultural projection plays a major role in unraveling the effect of a major social problem in typical Hausa society. This suggests that language is an essential means that allows people to fully exert their rights (to question societal issues) and participate in a democratic society. Thus, in practice, proper teaching and learning experiences can only be actualized when there is symphony between the concept and the context; due diligence has to be exerted to this end, especially in second language learning situations. Engaging the linguistic theory deployed in this study will enable learners to have a pictorial understanding of unfamiliar concepts. With the instrumentality of the SPEAKING acronym, the big picture of the lives and times of the insurgents' sufferers are made clear. This suggests the potency of 'acronymy' in teaching and learning new concepts, not only in language and literature but in other fields. In other words, the SPEAKING acronyms may be introduced as teaching aids in literary studies where students find it difficult to relate the fictitious world to the students' world. The culture and society sensitive theory, will be handy a tool for instructors whose goal are to inculcate analytical skills in learners.

Furthermore, Yerima's Pari is rich in many other language issues that could be unearthed with the many linguistic theories available to language experts. There is for instance, a preponderance of proverbs known chiefly among the northerners which can be studied to reveal more of their culture to the reading public. In future studies, the SPEAKING acronyms could be combined with related theories to have a robust linguistic appreciation of texts.

The author's use of English to present these Hausa proverbs highlights the fact that English can no longer be restricted to a people. It blends with other languages in the multilingual setting it finds itself. Hence, languages, especially, 'English are mobile objects moving around communities in intensive ways, on the rhythm of globalizing flows of commodities, people, messages and meanings' (Blommaert, 2010, p. 131). Language should not be perceived as a rigid phenomenon; thus, our environmental perception of language in societies requires adjustments to our understanding of the use of it, especially English in multilingual settings. This is very important since cultures provide diverse ways of interpreting the environment and the world, as well as relating to other people. When we recognize that other people can see the world differently, we use language; in this case, English, to capture the concept as much as possible, so that their interpretations of such concepts may be near perfect. It has been the constant endeavor of human beings to gain more knowledge about this world. In Pari, the author has made this possible by using language in text as a medium to express reason and make sense of human perceptions.

\section{References}

Adebileje, A., \& Atunde, O. (2014). A discourse analysis of language use in Femi Osofisan's The Midnight Blackout. Journal of English Language and Literature, 2, 135-140. https://doi.org/10.17722/jell.v2i1.62

Balogun, T. (2013). An endangered Nigerian indigenous language: The case of Yorùbá language. African Nebula, $6,70-81$.

Blommaert, J., \& Maly, I., (2014). Ethnographic linguistic landscape analysis and social change: A case study. Working Papers in Urban Languages and Literacies, 133, 2-20.

Bloommaert, J. (2010). The sociolinguistics of globalization. Cambridge University Press. https://doi.org/10.1017/CBO9780511845307 
Diamond, A. (1959). The history and origin of language. Metheun and Co.

Douglas, B. (2000). Principles of language learning and teaching ( $4^{\text {th }}$ ed.). Longman.

Hymes, D. (1974). Foundations in sociolinguistics: An ethnographic approach. University of Pennsylvania Press.

Jacquemet, M. (2005). Transidiomatic practices: Language and power in the age of globalization. Language and Communication, 25 (3), 257-277. https://doi.org/10.1016/j.langcom.2005.05.001

Kirby, G. R., Goodpaster, J. R., \& Levine, M. (2002). Critical thinking. Pearson Publishing House. https://doi.org/10.9774/GLEAF.4700.2002.au.00009

Matei, M. (2009). The ethnography of communication. Philology and Cultural Studies, 2(51), 152-165.

Pennycook, A. (2007). Global Englishes and transcultural flows. Routledge. https://doi.org/10.4324/9780203088807

Saville-Troike, M. (2003). The ethnography of communication: An introduction ( $3^{\text {rd }}$ ed.). Blackwell. https://doi.org/10.1002/9780470758373

Unuabonah, F. (2008). Ethnography of communication in doctor-pregnant woman conversations in selected hospitals in Ibadan, Nigeria. Papers in English and Linguistics, 9, 228-239.

Yerima, A. (2016). Pari. Kraftgriot. 
Adebola, A., \& Daniel, F.

30 Consortia Academia Publishing (A partner of Network of Professional Researchers and Educators) 